Published in final edited form as:

Clin Imaging. 2018 ; 52: 180-182. doi:10.1016/j.clinimag.2018.07.022.

\title{
Women in academic musculoskeletal radiology
}

\author{
Kate Anne Harrington ${ }^{*}$, Gregory Chang \\ Department of Musculoskeletal Radiology, NYU Langone Health, New York, USA
}

\begin{abstract}
Purpose: To determine the proportion of women working in academic musculoskeletal (MSK) radiology divisions and how this compares to national benchmarks for women in academic medicine.
\end{abstract}

Materials and methods: A list of academic radiology departments in the United States was compiled using the U.S. News and World Report listing of Best Hospitals for Orthopedics and Rheumatology to aid in department selection. Faculty information for MSK radiology divisions was obtained using websites pertinent to each department. Figures were obtained from the Association of American Medical Colleges and used as a benchmark for comparison.

Results: The 25 top-ranked hospitals with MSK radiology divisions were identified, with a total of 215 MSK trained radiologists. Female radiologists made up 33\% of the MSK trained faculty (n $=71$ ). This compares to $38 \%$ of fulltime female faculty in academic medicine. 79 assistant professor roles were identified, of which $35 \%$ were women $(n=28) .34 \%$ of associate professors were women $(n=11)$. Only $23 \%$ of professors were women $(n=10)$; this compares with $21 \%$ of female professors in academic medicine. Six MSK radiologists held either chair or vice-chair roles and three of these were women. Of the 24 chief or director roles identified, $30 \%$ of these were held by women.

Conclusion: The proportions of women within various roles in academic MSK radiology are similar to and in some instances higher than corresponding national benchmarks. However, there remains a discrepancy between the sexes with an overall male majority. Awareness of this fact is the first step required to help correct this imbalance.

\section{Keywords}

Women; Academia; Musculoskeletal radiology; Career; Professor

\section{Introduction}

Since 1849 , the year the first woman obtained a medical degree in the United States, the number of female graduates from medical colleges has increased, albeit slowly [1]. In the 2007-2008 academic year gender parity was finally achieved when $49.3 \%$ of the graduating medical student population were women [2]. Although a similar number of men and women begin their respective medical careers, there is a progressive relative decrease in women advancing through each stage of their career, with women in the minority in leadership roles

*Corresponding author. harringtonkatea@gmail.com (K.A. Harrington). 
and academic appointments today. For example in 2015, in the specialty of obstetrics and gynecology, $82.8 \%$ of residents were women, yet only $31 \%$ of full professors of obstetrics and gynecology were women [3]. Diagnostic Radiology has traditionally been a male dominated clinical specialty with female radiology residents being underrepresented when compared with other medical specialties [4]. This status quo has remained unchanged in over a decade with $27.4 \%$ of radiology residents being women in 2005 compared with $25.8 \%$ of radiology residents in 2015 [5]. Once female radiologists make faculty, the apparent increasing disproportion of their male counterparts in academic appointments as seen across all other medical specialties, is also mirrored in diagnostic radiology. For example, in 2015, 37\% of radiology instructors were women, and as rank progressed from assistant professor to associate professor and finally full professor there was a corresponding decline in female academic appointments. Specifically, 32\% of assistant professors, 30\% of associate professors and $21 \%$ of full professors were women [3]. Interestingly however, a study looking at faculty rank and appointments of radiologists in 2014 saw no difference in faculty rank between male and female radiologists following adjustments for age, publications, awarded grants and clinical trial involvement [6]. A second similar study demonstrated that radiology, along with hematology/oncology, were the only two medical specialties to have no statistical difference between male and female full professorship status rank following adjustments. Men were significantly more likely than women to be full professors in every other medical specialty [7].

The aim of this project was to firstly document the number of women who are trained in the subspecialty of musculoskeletal (MSK) radiology, compared to women in diagnostic radiology. Academic positions held by women in MSK radiology was also evaluated and compared to national benchmarks in diagnostic radiology and all of academic medicine as compiled by the Association of American Medical Colleges. Finally, the number of women in leadership roles was documented.

\section{Materials and methods}

A list of academic radiology departments across the United States was compiled using the U.S. News and World Report listing of Best Hospitals for Orthopedics and Rheumatology in 2017 to aid in department selection. Best Hospitals for Orthopedics is ranked annually based on data obtained for performance ratings, patient outcome, patient death rates etc., whereas Best Hospitals for Rheumatology is determined by response from surveys of specialist physicians [8]. Once a list was compiled, the radiology departments at the combined topranking 25 hospitals were then evaluated. Faculty information for each MSK radiology division was obtained using websites pertinent to each department. Omitted information on department webpages were supplemented by the use of Doximity, an online database which lists age, sex, specialty and faculty rank of practicing physicians across the United States. Each faculty member was noted as well as any academic appointments and leadership roles they held. Figures for academic positions held nationally were obtained from the Association of American Medical Colleges (AAMC) and used as a benchmark for comparison. The AAMC provide current and historical data on a list of a variety of topics pertinent to medical schools and teaching hospitals and their graduates. 


\section{Results}

25 MSK radiology divisions were first identified amongst the top ranked hospitals for rheumatology and orthopedic surgery with a total of 215 MSK trained radiologists identified. On average, each department had 9 MSK trained radiologists, with a range of 3 to 22 MSK radiologists. Female radiologists made up 33\% of the MSK trained faculty $(\mathrm{n}=71)$. This compares with $30 \%$ of fulltime female faculty in diagnostic radiology and $38 \%$ of fulltime female faculty in academic medicine.

\subsection{Academic appointments}

A total of 79 MSK faculty held assistant professor roles, of which $35 \%$ were occupied by female faculty $(n=28)$. This compares with $37 \%$ of assistant professors who are women in diagnostic radiology nationally. Taking all clinical specialties in medicine together, $43 \%$ of assistant professors are women.

32 associate professor roles amongst MSK radiologists were identified of which, 34\% of faculty were female $(n=11)$. This is slightly higher than in both diagnostic radiology and academic medicine where only $32 \%$ and $33 \%$ are women respectively.

At the professor level, $23 \%$ were female $(n=10)$; this compares with $21 \%$ of women in diagnostic radiology and $20 \%$ of women in academic medicine.

\subsection{Leadership roles}

Six MSK radiologists held either chair or vice-chair roles in their respective radiology departments and 3 of these, or $50 \%$, were female; this compares to $18 \%$ of female department chairs in the department of radiology and $16 \%$ of female department chairs across medicine [9]. Of the 24 chief or director roles identified, $30 \%$ of these were held by women; this compares to a national benchmark of $24 \%$ for women in academic medicine.

Finally, only $25 \%$ of the roles specific to education, such as fellowship or residency program director, were filled by women $(n=4)$.

\section{Discussion}

Despite the increasing number of women in medicine there continues to be a disparity between men and women in academic appointments and leadership roles, events which occur typically as ones' career progress. In the first instance, the proportion of women in diagnostic radiology and the MSK subspecialty remains at a lower level than that of other specialties in academic Medicine. The reasons for this are not entirely clear, but cited causes include the lack of female role models and mentors in radiology [10]. Radiology has many similarities with the physical sciences and STEM (science, technology, engineering and mathematics) disciplines, with women historically compromising a smaller percentage within these areas of study.

This disparity remains between men and women in academic appointments as their career progresses. A cohort study demonstrated that the proportion of women that advance through 
the senior ranks of academic medicine is lower than that of their male counterpoints, despite the increasing number of women graduating from medical school and the greater than expected number of women that hold a faculty position [11]. While it is clear that there is an increase in absolute numbers of women in each academic rank, women are still less likely to attain a senior rank position than men [11]. Some studies have shown that men publish more than women and one may argue that men therefore warrant the promotion ahead of women, however this disparity in publication productiveness is probably the outcome of an unbalanced workplace and reflect the many institutional barriers that women have been proven to face in the early stages of their academic career. Tangible and real institutional barriers that have been described include less access to laboratory space, secretarial support and decreased grant support for women $[12,13]$.

Some studies recently demonstrated that there were no significant differences between men and women and full professorship appointments within the subspecialty of diagnostic radiology once adjustments, such as age, were made [7]. Another recent study which compared h-indices of academic MSK radiologists demonstrated that at lower academic levels, a lesser number of women were promoted relative to their male peers even when hindices were comparable, suggesting that research productivity alone did not account for selection in promotion at earlier stages of women's academic career [14].

Therefore, cultural and gender differences in life goals and roles surely also have a part to play, particularly in the earlier part of a women's career. This usually coincides with women's childbearing and child rearing years, often put on hold during medical studies in earlier years. In an attempt to explain the differences in women's career progression a study looked at gender differences of nonprofessional responsibilities in young academic physicians and found that women with children spent more time on domestic activities than men with children, and were also more likely to lose time at work in the event of unexpected disruptions to child care [15].

Women with children were shown to publish less and progress slower through their careers than men with children. Men and women without children had no differences in number of publications or rate of career progression [13]. Not only do women have less time to devote to their career advancement but the gender roles women conform to also allow men to get ahead. A survey done on men in leadership roles attributed the extent of their own career advancement to sacrifices made by their partners on their behalf [16].

We have demonstrated that in the subspecialty of MSK radiology the proportion of female faculty in the specialty is not only comparable to that of diagnostic radiology but even performs slightly better at the higher academic levels such as associate and full professor level. The fact remains however, that a gender imbalance persists across all levels of academic radiology. This imbalance is also reflected in women in leadership roles, with only a minority in lead roles such as chair, director or chief.

First there needs to be recognition and an acknowledgment of the disparity before trying to discover where the disparities lie and how and why these disparities are allowed to exist. Once identified, clear interventions and support programs with prescribed outcomes can be 
designed. Recruitment of more female radiologists can be aimed firstly at medical students, with placement of female radiologists in teaching and mentoring roles. Without specific interventions, the low numbers of women entering radiology will perpetuate the lack of female role models in the specialty, discouraging young doctors from entering radiology and continue the cycle of the long-standing gender gap. Within residency itself, the creation of a specific mentoring program for all residents should ensure the continued mentorship of female residents and allow them to work closely with female role models. A pilot program of peer mentorship for academic advancement set up amongst female physicians in a large academic practice resulted in an increase in all academic activity, most notably in increased number of publications in research journals and promotion of academic rank [17]. Visiting professorships can be effective in not only providing more female roles models in departments, but also allow building a network amongst female radiologists.

The Association of American Colleges has set up an advocacy group called Group on Women in Medicine and Science (GWIMS) which serves to create a networking and support system for women in medicine and science and seeks to encourage and nominate female peers in leadership and mentorship roles, amongst other goals. While it is important for women to support other women, collaboration with male counterparts in breaking down the perceived and real, institutional and cultural, barriers that are in place today is also likely to be required.

While this may mean tackling and correcting definable and tangible pieces of the gender imbalance, they alone may not be enough considering the pervasive and deep cultural differences that run deep. A fundamental restructuring of the "typical working day" and specified steps for career progression, originally designed to accommodate the traditional figure that was typically the male head of the single-income family, may be the change that is required to ensure an equitable and balanced work place. Whatever form that change may come in, an emphasis on encompassing the nonacademic responsibilities and personal roles that both men and women also assume in their lives is likely to be also necessary.

This study has a number of limitations. Firstly, this was not an exhaustive study on MSK radiologists in academia. Only a subsection of MSK radiologists were captured, and those looked at were at "top-ranking", renowned hospitals across the United States. While this allowed us to look at the role of women in these departments, it may not be entirely representative of the subspecialty as a whole. Next, the data collection relied on up to date departmental websites pertinent to each hospital.

In conclusion, the proportions of women within various roles in academic MSK radiology are similar to and in some instances higher than corresponding national benchmarks for diagnostic radiology and academic medicine. However, a discrepancy remains between men and women in higher academic posts, likely due to institutional and cultural barriers women have been proven to face.

\section{Funding}

This research did not receive any specific grant from funding agencies in the public, commercial, or not-for-profit sectors. 


\section{References}

[1]. Dr. Elizabeth Blackwell's graduation: an eye-witness account by Margaret Munro De Lancey Available from: https://web.archive.org/web/20031212033218/http://academic.hws.edu/library/ archives/pdfs/tripp.pdf, Accessed date: 1 December 2017.

[2]. Medical students, selected years 1965-2015 Available from: https://www.aamc.org/download/ 481178/data/2015table1.pdf, Accessed date: 1 December 2017.

[3]. Distribution of full-time women MD faculty by department and rank, 2015 Available from: https:// www.aamc.org/download/481182/data/2015table3.pdf; 2015, Accessed date: 1 December 2017.

[4]. Chapman CH, Hwang W-T, Both S, Thomas Jr Charles R, Deville C. Current status of diversity by race, Hispanic ethnicity, and sex in diagnostic radiology. Radiology 2014;270(1):232-40. [PubMed: 23901125]

[5]. Distribution of residents by specialty, 2005 compared to 2015. Available from: https:// www.aamc.org/download/481180/data/2015table2.pdf; 2015-2016.

[6]. Kapoor N, Blumenthal DM, Smith SE, Ip IK, Khorasani R. Gender differences in academic rank of radiologists in U.S. medical schools. Radiology 2017;283(1):140-7. [PubMed: 27768540]

[7]. Jena AB, Khullar D, Ho O, Olenski AR, Blumenthal DM. Sex differences in academic rank in US medical schools in 2014. JAMA 2015;314(11):1149-58. [PubMed: 26372584]

[8]. Comarow A. How and why we rank and rate hospitals Available from: https://health.usnews.com/ health-care/best-hospitals/articles/faq-how-and-why-we-rank-and-rate-hospitals; 2017, Accessed date: 16 January 2018.

[9]. Distribution of Chairs by Department, Gender and Race/Ethnicity 2015. Association of American Medical Colleges; 2015.

[10]. Roubidoux MA, Packer MM, Applegate KE, Aben G. Female medical students' interest in radiology careers. J Am Coll Radiol 2009;6(4):246-53. [PubMed: 19327657]

[11]. Nonnemaker L Women physicians in academic medicine: new insights from cohort studies. $\mathrm{N}$ Engl J Med 2000;342(6):399-405. [PubMed: 10666431]

[12]. Tesch BJ, Wood HM, Helwig AL, Nattinger AB. Promotion of women physicians in academic medicine. Glass ceiling or sticky floor? JAMA 1995;273(13):1022-5. [PubMed: 7897785]

[13]. Carr PL, Ash AS, Friedman RH, Scaramucci A, Barnett RC, Szalacha L, et al. Relation of family responsibilities and gender to the productivity and career satisfaction of medical faculty. Ann Intern Med 1998;129(7):532-8. [PubMed: 9758572]

[14]. Qamar SR, Khurshid K, Jalal S, Bancroft L, Munk PL, Nicolaou S, et al. Academic musculoskeletal radiology: influences for gender disparity. Skeletal Radiol 2018;47(3):381-7. [PubMed: 29260259]

[15]. Jolly S, Griffith KA, DeCastro R, Stewart A, Ubel P, Jagsi R. Gender differences in time spent on parenting and domestic responsibilities by high-achieving young physician-researchers. Ann Intern Med 2014;160(5):344-53. [PubMed: 24737273]

[16]. Yedidia MJ, Bickel J. Why aren't there more women leaders in academic medicine? The views of clinical department chairs. Acad Med 2001;76(5):453-65. [PubMed: 11346523]

[17]. Files JA, Blair JE, Mayer AP, Ko MG. Facilitated peer mentorship: a pilot program for academic advancement of female medical faculty. J Womens Health (Larchmt) 2008;17(6):1009-15. [PubMed: 18681821] 